\title{
Cuidado às adolescentes grávidas: perspectiva e atuação de agentes comunitários de saúde
}

\author{
Care to pregnant adolescents: perspectives and performance of community health agents \\ Cuidado a las adolescentes embarazadas: perspectiva y actuación de agentes \\ comunitarios de salud
}

\author{
Maiara Paixão de Oliveiral'; Nayara Mendes Cruz II; Laísla Alves MouraIII; Jaqueline Gonçalves Moura ${ }^{I V}$; \\ Rodrigo Mendes Nonato Coelhov; Mônica Cecília Pimentel de Melo ${ }^{\text {VI }}$
}

\begin{abstract}
RESUMO: O agente comunitário de saúde deve ter incorporado, em sua formação, conceitos que valorizam as necessidades das grávidas adolescentes. O estudo objetivou analisar o cuidado às grávidas adolescentes através da perspectiva e atuação de agentes comunitários de saúde. Trata-se de um estudo qualitativo e descritivo, com agentes que acompanhavam grávidas adolescentes. Foram realizadas cinco entrevistas semiestruturadas e acompanhadas de observações em diário de campo, de setembro a outubro de 2010, em Juazeiro-BA, segundo análise de conteúdo de Bardin. Comprovou-se que o agente enfrenta muitas dificuldades enquanto profissional de saúde pela falta de conhecimento suficiente resultante da carência de estratégias de educação permanente. O fato de residir na comunidade mostrou-se decisivo na criação de vínculos com a adolescente. Fato importante é que os sujeitos buscam realizar o cuidado mesmo com todos os obstáculos e dificuldades encontrados. Palavras-Chave: Saúde da família; gravidez; adolescência; enfermagem.
\end{abstract}

\begin{abstract}
Out of their training, community health agents must have incorporated concepts that value the needs of pregnant adolescents. This study aims at analyzing the care to pregnant teenagers through the perspective and performance of community health agents. This is a qualitative, exploratory and descriptive study, with agents that assisted pregnant adolescents. Five semi-structured interviews were conducted and followed up by notes in field journal, from September to October, 2010, in Juazeiro-BA, Brazil, on the basis of Bardin's content analysis. As health professionals, agents were found to have quite a few difficulties due to their insufficient skills resulting from lack of permanent education strategies. The fact they were community members proved to be decisive in the creation of links with the teenager. It must be highlighted that the subjects endeavor to give care despite the hindrances they come across.

Keywords: Family health; pregnancy; adolescence; nursing.
\end{abstract}

RESUMEN: El agente comunitario de salud debe haber incorporado en su formación conceptos que valoricen las necesidades de las embarazadas adolescentes. El estudio pretende analizar el cuidado a las embarazadas adolescentes a través de la perspectiva y actuación de agentes comunitarios de salud. Se trata de un estudio cualitativo y descriptivo, con agentes que acompañaban a embarazadas adolescentes. Se realizaron cinco entrevistas semiestructuradas y acompañadas de observaciones en diario de campo, de setiembre a octubre de 2010, en Juazeiro-BA, según análisis de contenido de Bardin. Se comprobó que el agente enfrenta muchas dificultades como profesional de sanidad por la falta de conocimiento suficiente como resultado de la carencia de estrategias de educación permanente. El hecho de residir en la comunidad se mostró decisivo en la creación de vínculos con la adolescente. Hecho importante es que los sujetos intenten realizar el cuidado, incluso con todos los obstáculos y dificultades encontrados.

Palabras Clave: Salud de la familia; embarazo; adolescencia; enfermería.

\section{INTRODUÇÃO}

A gravidez na adolescência é considerada como um desafio no cenário sociopolítico e econômico do Brasil, devido às repercussões para o sistema de saúde e de educação, sendo associada a riscos sociais, biológicos e pessoais que comprometem o desenvolvimento da adolescente e seu filho ${ }^{1}$. Essa associação prevalece até os dias atuais, sendo que o conceito de risco e vulnerabilidade é divulgado pela medicina obstétrica, sem a preocupação com o contexto em que a gravidez acontece, abrangendo fatores de ordem econômica, social e cultural, em meio aos quais, as relações de gênero se concretizam².

'Enfermeira. Graduada pela Universidade Federal do Vale do São Francisco. Petrolina, Pernambuco, Brasil. E-mail: maiara.italo@hotmail.com.

"Graduanda em Enfermagem, 7ํㅗㄴ semestre, Universidade Federal do Vale do São Francisco. Petrolina, Pernambuco, Brasil. E-mail: blaymendes@hotmail.com ${ }^{\mathrm{III}}$ Graduanda em Enfermagem, $7^{\circ} \stackrel{ }{ }$ semestre, Universidade Federal do Vale do São Francisco. Petrolina, Pernambuco, Brasil. E-mail: laislaalves19@ gmail.com. IV Graduanda em Enfermagem, $7 \stackrel{0}{ }$ semestre, Universidade Federal do Vale do São Francisco. Petrolina, Pernambuco, Brasil. E-mail: enf.jaquelinemoura@gmail.com. vGraduando em Enfermagem, $7^{\circ} \stackrel{0}{ }$ semestre, Universidade Federal do Vale do São Francisco. Petrolina, Pernambuco, Brasil. E-mail: rodrigo.coelho.mendes@gmail.com.

VlEnfermeira. Docente da Universidade Federal do Vale do São Francisco, Área Saúde da Mulher e Gênero. Mestre em Enfermagem. Doutoranda em Enfermagem pela Universidade Federal do Ceará. E-mail: monquinamelo@gmail.com. 
Na busca para promover ações de cuidado às gestantes adolescentes, o Ministério da Saúde ${ }^{3}$ centra seus esforços em estratégias que valorizam as relações humanas, a produção de vínculos, o acolhimento e a autonomia do usuário no cuidado. Esse modelo assistencial prioriza o trabalho multidisciplinar no qual todos devem se identificar com uma proposta de atendimento que exige criatividade e iniciativa para trabalhos comunitários e em grupo ${ }^{4}$.

Os agentes comunitários de saúde (ACS) possuem um papel muito específico que os diferenciam dos demais elementos da equipe. Os mesmos conhecem intimamente a realidade local porque são parte da comunidade. Representam uma possibilidade de trazer para dentro das equipes de saúde o olhar da população, revelando necessidades de um ponto de vista diferente e que, portanto, abre as portas para um universo novo de intervenções ${ }^{5}$.

Portanto, partindo-se do princípio de que o ACS, através da estratégia de saúde da família (ESF), deva ter incorporado, em sua formação, conceitos que valorizam as necessidades das mulheres, com ações de cuidado, em específico, o cuidado às adolescentes grávidas, o estudo busca responder a seguinte questão de pesquisa: Qual a perspectiva e atuação do agente comunitário de saúde, inserido na ESF, acerca do cuidado de grávidas adolescentes?

Buscou-se analisar o cuidado às grávidas adolescentes através da perspectiva e atuação do agente comunitário de saúde.

\section{REVISÃO DE LITERATURA}

Todo usuário do serviço de saúde, independente do perfil sócio-econômico-cultural, busca no profissional de saúde uma possibilidade de escuta e resolução do seu problema. Ele deseja ser acolhido, orientado, compreendido em suas necessidades, pois assim sente-se confiante de que está seguro e bem amparado. Comparando com os adolescentes, sua grande maioria sente vergonha, medo de ser repreendido e intimidado pela figura do profissional, fazendo da atitude de procurar a unidade de saúde um ato difícil e que necessita de certa coragem ${ }^{6}$.

Por esse motivo, é fundamental que o adolescente sinta-se reconfortado e respeitado, para que possa confiar e obter as informações que necessita, através de uma fonte segura, e não pela mídia ou pelos amigos, como muitos recorrem, obtendo, muitas vezes, a informação de forma errada?

O ACS tem papel fundamental na captação dos adolescentes para as unidades básicas de saúde (UBS). Durante suas visitas domiciliares deve incentivar os adolescentes a procurarem a UBS de referência diante de qualquer problema ou dúvida, informando-os sobre a existência de serviços especializados e das atividades que ocorrem e que são voltadas para este público. É preciso lembrar que muitos adolescentes deixam de procurar ajuda e/ou tratamento porque desconhecem os serviços que lhes são oferecidos e temem o tipo de receptividade que podem encontrar na UBS?

O ACS precisa estar atento às adolescentes gestantes da comunidade e orientá-las sobre a importância do pré-natal e onde elas podem realizá-lo. Atividades em grupo podem ser organizadas para trabalhar as temáticas como gravidez na adolescência, amamentação, imunização, DST, planejamento familiar, entre outros, não apenas para essas futuras mães como para todos os adolescentes. Quando estão em grupo os adolescentes sentem-se mais seguros e confiantes para interagir com os outros e exporem suas dúvidas para os colegas e para o coordenador do grupo, que pode ser um profissional da saúde, inclusive o próprio $\mathrm{ACS}^{8}$.

É importante ressaltar que existem grupos de adolescentes e jovens em situações específicas de agravos, que devem ser priorizados na atenção à saúde. Isso implica no desenvolvimento de estratégias diferenciadas, como a criação de mecanismos de integração com as instituições que lidam com esses grupos ${ }^{9}$.

\section{Metodologia}

Trata-se de uma pesquisa qualitativa de caráter descritivo. Foi realizada na Unidade Saúde da Família Tabuleiro, no município de Juazeiro - BA. A amostra foi composta por cinco agentes comunitários de saúde que estavam acompanhando grávidas adolescentes, com idade entre 10 e 19 anos, em qualquer trimestre de gestação e cadastradas no pré-natal. Deveriam estar atuando na comunidade há mais de um ano, considerando-se importante para a pesquisa a criação de vínculo com a gestante. Aqueles que concordassem em participar deveriam assinar o termo de consentimento livre e esclarecido (TCLE). Foram excluídos os sujeitos que não aceitaram participar da pesquisa, que tivessem menos de 1 ano de atuação na comunidade, não estivessem acompanhando grávidas adolescentes em sua área e/ou fossem portadores de necessidades especiais que pudessem interferir na comunicação entrevistado-entrevistador.

O período de coleta foi compreendido entre setembro a outubro de 2010, logo após a aprovação pelo Comitê de Ética em Pesquisa da Universidade Federal do Vale do São Francisco (UNIVASF) sob o protocolo $n^{\circ}$ 0038.0.441.441-10. Como garantia do anonimato dos entrevistados, as mesmas foram identificadas através de números, de acordo com a ordem das entrevistas.

Para a coleta de dados, primeiramente, os ACS foram convidados a participar de uma roda de conversa, na qual foram apresentados os objetivos da pesquisa e sanadas as dúvidas. Foram feitos os agendamentos para acompanhamento da visita domiciliária realizada pelo ACS, pois foi utilizado como instrumento de 
coleta, nessa etapa, a observação não-participante e não-estruturada, registrada na forma de diário de campo, o qual continha alguns dados socioeconômicos e obstétricos da gestante, fornecidos pelo ACS. O número de visitas observadas para cada ACS dependeu do quantitativo de grávidas adolescentes que os mesmos tinham em sua localidade de atuação no período da coleta. Dessa forma, tentou-se abranger um universo maior do objeto pesquisado.

Logo após a visita, procedeu-se à entrevista semiestruturada, na qual os dados foram gravados em áudio e transcritos na íntegra, sendo realizadas apenas correções ortográficas e de vícios de linguagem, sem que houvessem perdas na essência das falas. A análise dos dados foi fundamentada na análise de conteúdo de Bardin ${ }^{10}$ com resultados interpretados para que fossem significativos e válidos.

\section{Resultados e Discussão}

A idade das gestantes variou de 15 a 18 anos. No quesito nível de escolaridade, uma tinha o ensino médio completo; uma o ensino médio incompleto e se encontrava estudando; três o ensino fundamental incompleto, sendo que uma parou os estudos na $8^{a}$ série. Entre elas, quatro permanecem com os seus parceiros e apenas uma era solteira. A cor/etnia predominante foi a parda. Observou-se entre as gestantes visitadas um caso de aborto.

Entre os ACS que participaram do estudo, todos tinham ensino médio completo e eram casados. A idade variou de 30 a 42 anos, com tempo de atuação variando de 2 a 18 anos. A religião que prevaleceu foi a católica, e na opção de capacitação em saúde do adolescente, apenas dois a obtiveram.

Os conteúdos das entrevistas e observações coletadas com os ACS foram distribuídas em categorias e subcategorias para melhor verificação dos resultados.

\section{Papel do ACS ao lidar com as gestantes adolescentes}

Esta categoria abrange duas subcategorias analisadas a seguir.

Cuidados na gestação e o preparo para a maternidade: 0 predomínio da técnica

Foram encontrados nesta subcategoria orientações de cuidado na gestação e o preparo para a maternidade da gestante adolescente, feitas pelo ACS, baseadas em técnicas assistenciais, como: cuidados com a vacina, consulta pré-natal, controle de peso e pressão arterial, cartão da gestante, prevenção de complicações obstétricas, entre outros.

Para mim é orientar as futuras mães a forma correta de como cuidar da criança e orientar também para que ela tenha os devidos cuidados durante a gestação, para que não possa ter nenhum problema futuro, por exemplo: nas vacinas, no acompanhamento do feto que é feito pela enfermeira, acho que é isso. (Entrevista 1)

Eis as observações do diário de campo:

O ACS vai à casa da gestante; pergunta como a gestante está; adiciona os dados da gestante a sua ficha A; pergunta das consultas com a enfermeira, do que ela falou; do seu peso. Pede o cartão da gestante; fala da importância do pré-natal; olhou seus registros de vacinas, pressão arterial; questiona se ela está sentindo alguma coisa, alguma dor, queixa. Falou do número de consultas do pré-natal, pergunta se ela está tomando ácido fólico e sulfato ferroso e a gestante responde que está tomando. Orientou o uso do ácido fólico pela manhã; o uso de um óleo tópico no abdômen para evitar estrias. Orienta também que tem que amamentar e que o bebê tem que ficar coladinho com a mãe, sem a mãe ter que ficar em cima do bebê e que ela deve estar atenta às vacinas e às consultas do pré-natal e que caso ela sinta alguma coisa procure a unidade. (Observação 1)

Diante do relato e da observação mencionados, durante a visita domiciliar, confirma-se que o modelo clínico constitui o eixo norteador das práticas. Não que esse tipo de atenção não seja necessária, mas é preciso complementá-la com cuidados essenciais de escuta, valorizando as necessidades mais subjetivas da gestante, que também é adolescente e se encontra inserida em um determinado contexto socioeconômico.

Numa visão sob a perspectiva de gênero e dos direitos sexuais e reprodutivos, a qual retrata a mulher como sujeito social na busca pela construção e afirmação de sua identidade na sociedade atual, desvela-se a amamentação como uma possibilidade de escolha feminina para decidir sobre seu corpo e sua vida reprodutiva ${ }^{11}$.

Nessa mesma subcategoria surge a preocupação do ACS no cuidado gestacional associado com a temática do alto risco na gravidez adolescente.

Acompanhamento através da visita domiciliar. Informar para fazer o pré-natal, somente com a enfermeira ou médico na unidade de saúde. E é através do prénatal que a gestante tem como descobrir se a mesma tem uma gravidez de alto risco ou não, daí então, ela passa a ter um acompanhamento pelo profissional qualificado, até o nascimento da criança. (Entrevista 2)

São observações do diário de campo:

O ACS chega à casa da gestante, pergunta da gravidez, se está sentindo alguma coisa, se já foi à unidade, se foi vista pela enfermeira. Diz que seu pré-natal é de alto risco, porque já é sua quarta gestação com três abortos. Explica para a gestante que quando chega ao quinto ou sexto mês, ela sempre perde o feto, mas que graças a Deus nessa gestação está ocorrendo tudo certo com esse pré-natal. Orienta que a gestante vá à unidade para passar na enfermeira para pegar o encaminhamento para o hospital porque a gestante já está com 9 meses. (Observação 2) 
Os últimos relatos destacam o cuidado com a saúde de gestantes adolescentes no pré-natal de alto risco. Acrescenta também o encaminhamento da gestante para o atendimento diferenciado nesse serviço.

É fundamental que os serviços de saúde desenvolvam mecanismos próprios para a captação precoce dessas gestantes, proporcionando-lhes uma atenção pré-natal diferenciada realizada por profissionais sensibilizados em relação às suas condições específicas ${ }^{12}$.

Para além do cuidado técnico com as adolescentes

Nesta subcategoria, e possível identificar que o ACS, se empenha para se adequar às necessidades individuais das clientes, apesar de a observação revelar um maior predomínio da clínica para o desenvolvimento saudável da gestação, em detrimento da escuta e valorização das necessidades das adolescentes.

É orientar, encaminhar, posso dizer para você que até o que eu faço é independente da função, a gente faz mais do que exige, a gente serve de tanta coisa é de mãe, de amiga, de psicóloga é de tanta coisa. (Entrevista 4)

As observações do diário de campo destacaram:

ACS chega à casa da gestante. É uma casa de barro com quatro cômodos, onde moram 15 pessoas; algumas dormiam no chão, outras em rede; sem pia para lavar prato; sem lavanderia; cozinham à lenha. Dá boa tarde, pede o cartão da gestante, olha o cartão e a data de retorno da gestante para a unidade, pergunta das vacinas e verifica seus registros no cartão. Observa sua data provável de parto; pergunta se está sentindo alguma coisa; orienta a gestante do contato com gato - a pois na casa visitada tem gato como animal de estimação; explica a doença do gato - a toxoplasmose - e que a ela não deve ter contato com gato. A ACS pergunta sobre a alimentação e a ultrassonografia; e se ela está sentindo alguma coisa. A ACS orienta a gestante que se precisar de atendimento de urgência, a levará até a unidade para passar pela enfermeira (Observação 4)

Compete ao ACS, no exercício de sua prática, mobilizar e articular conhecimentos, habilidades, atitudes e valores requeridos pelas situações de trabalho, realizando ações de apoio em orientação, acompanhamento e educação popular em saúde a partir da concepção de saúde como promoção da qualidade de vida e desenvolvimento da autonomia diante da própria saúde ${ }^{13}$.

\section{Obstáculos frente ao papel do ACS no acom- panhamento de gestantes adolescentes}

Esta categoria foi subdividida em duas subcategorias, examinadas a seguir.

\section{Falta de capacitação}

Foi destacado o problema da falta de capacitação dos ACS, o qual acaba interferindo na sua atuação, através da falta de informação sobre como lidar com a gravidez na adolescência.
[...] a gente não está tendo treinamento há algum tempo. [...] Então, eu ensino como amamentar, como segurar, como ela se comportar quando tiver sentindo as dores, o que deve fazer se está fazendo o pré-natal direitinho [...] (Entrevista 3)

Um estudo desenvolvido sobre o ACS do Projeto QUALIS/PSF, no município de São Paulo, identificou que o ACS não dispõe de instrumentos e tecnologias, aqui incluídos os saberes para as diferentes dimensões esperadas do seu trabalho. Essa insuficiência faz com que ele acabe trabalhando com o senso comum, com a religião e, mais raramente, com os saberes e os recursos das famílias e da comunidade ${ }^{14}$.

O ACS e as questões de gênero: dificuldades em ser do sexo masculino

Nesta subcategoria foram evidenciadas, na coleta de informações das gestantes adolescentes, dificuldades do ACS por ser do sexo masculino.

As dificuldades interferem, até mesmo, devido eu ser homem. Poucas adolescentes confiam. Elas gostam de confiar mais nas agentes de saúde mulheres, elas gostam de conversar, mas até que na minha área não tem essa desconfiança, porque não foi escondida a gravidez delas; todas elas estão com companheiro, então eu não encontrei dificuldades (Entrevista 1)

Embora, em uma pesquisa, as adolescentes quando questionadas em relação às dúvidas sobre como evitar uma gravidez, citaram com maior freqüência o diálogo com o sexo masculino, representado em 32,2\% e diálogo com o sexo feminino em $27,1 \%$ das respostas ${ }^{15}$.

Os adolescentes relataram ainda na mesma pesquisa que os diálogos e o esclarecimento de dúvidas sobre sexo e gravidez na adolescência ocorriam com maior frequência com os amigos, todavia, enfatizaram também que dúvidas sobre a prevenção de gestação eram discutidas com os pais, mães e com profissionais de saúde ${ }^{15}$.

\section{Comparação entre o pré-natal de adolescentes e de adultas}

Esta categoria previu duas subcategorias discutidas a seguir.

\section{Imaturidade biológica e psicossocial}

Aqui se destacou a comparação entre o prénatal de adolescentes e de adultas relacionado com a imaturidade biológica e psicossocial.

Na minha opinião, creio que sim, porque a adolescente que está fazendo pré-natal tem que tomar bastante cuidado porque o corpo dela não está desenvolvido totalmente para ter uma gestação, por isso que ela tem que ter bastante cuidado. Tanto ela, quanto a enfermeira da unidade com aquela pessoa (Entrevista 1)

Sim! Porque as mulheres adultas, eu acho assim que elas já tem seu corpo formado, a adolescente não. A formação do seu corpo e a experiência de vida também, 
como se preparar para ter uma criança e depois que nascer a criança, se preparar para como saber cuidar daquela criança (Entrevista 2)

Percebeu-se que para esses ACS a gestação na adolescente é diferente da mulher adulta porque as transformações físicas da adolescente não estão completadas, e por isso, são consideradas gestantes biologicamente imaturas.

Adolescentes menores de 15 anos constituem um grupo de maiores riscos obstétricos, pois o seu crescimento pode sofrer interferências, haja vista a soldadura precoce das epífises, com prejuízos na estatura final; e pela maior possibilidade de desproporção céfalo-pélvica, devido a uma pelve demasiadamente estreita para a passagem do bebê. Estão também mais sujeitas a complicações do tipo eclâmpsia, anemia, parto prematuro e a terem recém-nascidos de baixo peso ${ }^{12}$ sendo estas últimas mais freqüentes em gestações que se repetem durante a adolescência, com intervalos interpartais curtos, menores do que dois anos?

Para muitas adolescentes, não existe uma relação direta entre gravidez e fim da juventude. Existem atitudes novas no universo adolescente, porém, são pouco conhecidas e contradizem o senso comum no que diz respeito aos desejos e dilemas desta faixa etária no tocante à maternidade ${ }^{16}$.

Necessidade de ações pré-natais específicas para gestantes adolescentes

Foi destacada a importância de ter ações educativas mais específicas para as grávidas adolescentes.

Então, o pré-natal da menina de quatorze anos que ainda é uma criança deveria ser diferente e ter mais convivência com as práticas, para elas estarem fazendo visitas na casa de uma gestante que está perto de ganhar e de uma que ganhou, para ela ver comoé o dia a dia de uma mãe. Que a criança dorme, acorda, arrota, faz cocô, como é que limpa e isso deveria ser mostrado na prática (Entrevista 5)

A atenção à grávida adolescente precisa atender às suas particularidades, num atendimento diferenciado para tal, como estabelecer dias e/ou horários específicos para a atenção das adolescentes; manter agenda aberta, sem necessidade de marcar consulta; o profissional deve ter disponibilidade para ouvir a adolescente, tirar suas dúvidas e prestar os esclarecimentos necessários, mesmo que necessite dispender mais tempo na consulta ${ }^{12}$.

\section{Aspectos facilitadores da relação ACS e gest- antes adolescentes}

\section{Criação de vínculos como fator de confiança}

Percebeu-se que as visitas domiciliares e o fato do ACS residir na comunidade contribuem para uma maior possibilidade de vínculos, estabelecendo uma relação de confiança e intimidade entre o usuário e o profissional.
[...] e a facilidade é a intimidade porque se você tem intimidade com ela e com a família você tem como chegar diretamente e perguntar. [...] facilita muito quando a gestante é daqui do bairro mesmo. Eu já vou logo perguntando, eu chamo fora da casa dela e converso, chamo até lá em casa e converso com ela (Entrevista 3)

O ACS possui um papel muito específico que o difere dos demais membros da equipe. Antes de tudo, são pessoas que convivem com a realidade e as práticas de saúde do bairro onde moram e trabalham, portanto identificam-se com a cultura, linguagem e os costumes de sua própria comunidade 5 .

Parceria com a enfermeira e a articulação com as redes de serviço

Onfermeiro é membro importantíssimo do desenvolvimento que de ações que visem a atenção integral aos adolescentes principalmente em relação a questões que imponham risco a sua integralidade. Junto com a equipe multiprofissional, ações humanizadas e que valorizem a vida devem ser implementadas para garantir a cidadania a esse público vulnerável ${ }^{17}$.

O que facilita é a proximidade em relação à enfermeira que a gente tem. De fazer palestras, de tá fazendo alguma iniciativa voltada para que essa gestante aprenda alguma coisa [...]. (Entrevista 5)

Eu acho que a gente faz o possível, mas eu acho que não é o suficiente para que elas não engravidem de novo. Eu acho que um trabalho em grupo, em toda a rede, eu acho que facilitaria para que elas não viessem a engravidar de novo. (Entrevista 4)

Situação sócio-econômica da clientela

Na fala seguinte, foi possível destacar que o ACS, que trabalha em microáreas menos favorecidas, possui mais autonomia com os usuários.

O que facilita na minha microárea é a carência deles, a vontade que eles têm de a gente ajudar, isso facilita porque eles gostam, precisam. [...] (Entrevista 4)

Muitas grávidas adolescentes chegam à UBS após o primeiro contato com o agente comunitário em sua casa, a partir da visita domiciliar, quando o ACS ao visitar uma gestante adolescente prioriza identificar o meio em que a gestante está inserida, sua condição sócio-econômica, situação conjugal e fatores de risco ${ }^{18}$.

É inegável que a gravidez na adolescência, especialmente nas faixas de renda mais pobres, contribui para a perpetuação de um ciclo de pobreza e carências e que uma atenção adequada pode minimizar tais consequências ${ }^{12}$.

\section{ConClusão}

O ACS possui papel fundamental no acompanhamento pré-natal da gestante adolescente, desde o seu cadastro até a visita puerperal. O ACS ao lidar 
com as gestantes adolescentes muitas vezes busca o preparo para a maternidade baseado na técnica, centrado no cartão da gestante, consultas, vacinas, medicações, deixando de lado a condição psicológica e social da cliente.

$\mathrm{Na}$ busca de um cuidado diferenciado com as adolescentes, muitas vezes, os ACS se deparam com obstáculos que dificultam o acompanhamento das gestantes e, mesmo com todas essas dificuldades, procuram atender às suas necessidades nas visitas domiciliares, retirando suas dúvidas, agendando a consulta pré-natal e orientando a sua importância, encaminhando para as vacinas de rotina e orientando as dúvidas que possam surgir com relação à amamentação.

É necessário que as carências sejam supridas começando pela capacitação dos ACS para que o atendimento à adolescente seja diferenciado e qualificado como preconizam as políticas públicas voltadas para esse grupo.

\section{REFERÊNCIAS}

1.Paraguassú ALCB, Costa MCO, Sobrinho CLN, Patel BN, Freitas JT, Araújo FPO. Situação sociodemográfica e de saúde reprodutiva pré e pós-gestacional de adolescentes, Feira de Santana, Bahia, Brasil. Ciênc Saúde Coletiva. 2005; 10: 373-80.

2.Melo MCP. Cuidado pré-natal a adolescentes sob o olhar da integralidade [dissertação de mestrado]. Salvador (BA): Universidade Federal da Bahia; 2007.

3.Ministério da Saúde $(\mathrm{Br})$. Secretaria de Atenção à Saúde. Manual de atenção à saúde do adolescente. Brasília (DF): Editora MS; 2006.

4.Loch-Neckel G, Seemann G, Eidt HB, Rabuske MM, Crepaldi MA. Desafios para a ação interdisciplinar na atenção básica: implicações relativas à composição das equipes de saúde da família. Ciênc Saúde Coletiva. 2009; 14: 1463-72.

5.Duarte LR, Silva DSJR, Cardoso SH. Construindo um programa de educação com agentes comunitários de saúde. Interface Comun Saúde Educ. 2007; 11: 439-47. 6.Rezende FM. O ir e vir dos usuários nas unidades da saúde da família [dissertação de mestrado em enfermagem]. Belo Horizonte (MG): Universidade Federal de Minas Gerais; 2007.
7.Ministério da Saúde (Br). Secretária de Saúde de São Paulo. Manual de atenção à saúde do adolescente. São Paulo: SMS; 2013.

8.Ministério da Saúde (Br). Secretaria de Atenção à Saúde. Área de Saúde do Adolescente e do Jovem. Marco legal: saúde, um direito de adolescentes. Brasília (DF): Editora MS; 2007.

9.Ministério da Saúde (Br). Secretaria de Atenção à Saúde. A saúde de adolescentes e jovens: uma metodologia de auto-aprendizagem para equipes de atenção básica de saúde: módulo básico. Brasília (DF): Editora MS; 2007.

10.Bardin L. Análise de conteúdo. Tradução por Luís Antero Reto e Augusto Pinheiro. Lisboa (Pt): Edições 70; 2004.

11.Mendonça JFS. Mulher e mãe, uma visão da maternidade por docentes/mães da UNIR [relatório de pesquisa PIBIC]. Porto Velho (R): Universidade Federal de Rondônia; 2004.

12.Ministério da Saúde (Br). A adolescente grávida e os serviços de saúde do município. Brasília (DF): Gráfica MS; 2013.

13.Ministério da Saúde (Br). Secretaria de Gestão do Trabalho e da Educação na Saúde. Departamento de Gestão da Educação na Saúde. Perfil de competências profissionais do agente comunitário de saúde. Brasília (DF): Editora MS; 2013.

14.Silva JA. O agente comunitário de saúde do Projeto QUALIS: agente institucional ou agente de comunidade? [tese de doutorado]. São Paulo: Universidade de São Paulo; 2001.

15.Borges ALV, Nichiata LYI, Schor N. Conversando sobre sexo: a rede sociofamiliar como base de promoção da saúde sexual e reprodutiva de adolescentes. Rev Latino-Am Enfermagem. 2006; 14:422-7.

16.Costa TJNM. Gravidez na adolescência: um estudo de caso sobre a maternidade na faixa de 10 a 14 anos em Juiz de Fora - MG [dissertação de mestrado]. Rio de Janeiro: Universidade do Estado do Rio de Janeiro; 2002. 17.Costa RF, Queiroz MVO, Zeitoune RCG. Cuidado ao adolescente: contribuições para a Enfermagem. Rev enferm UERJ. 2012; 20:197-202.

18.Ministério da Saúde (Br). Secretaria de Atenção à Saúde. Departamento de Atenção Básica. Guia Prático do Agente Comunitário de Saúde. Brasília (DF): Editora MS; 2009. 